\title{
Tecnologia da informação e integração das redes logísticas
}

\section{Information technology and logistics network integration}

\author{
Regina Meyer Branski ${ }^{1}$ \\ Fernando José Barbin Laurindo²
}

\begin{abstract}
Resumo: A integração das atividades logísticas constitui um grande desafio e envolve, além da empresa, seus parceiros externos. As tecnologias de informação têm papel central neste processo, já que fornecem a infraestrutura e os aplicativos que permitem a troca de informação necessária para a integração. O trabalho tem como objetivo apresentar um modelo - baseado nas tecnologias de informação - para análise das fases de integração externa entre operadores e os demais agentes da rede logística. A análise foi construída a partir de um estudo de casos realizado com quatro operadores logísticos com atuação no mercado brasileiro. A pesquisa identificou as tecnologias utilizadas pelos operadores no processo logístico e analisou sua contribuição para o estabelecimento da logística integrada baseando-se em três parâmetros - integração dos fluxos de materiais, produtos e informação; sua coordenação; e o estabelecimento de parcerias entre os agentes. A partir dos elementos levantados na pesquisa, o estudo apontou a existência de três níveis de integração externa entre o operador e os demais agentes da rede: plena, parcial e inexistente. A rede logística constitui uma rede de valor quando há integração plena e o estabelecimento de parcerias entre os operadores e os demais agentes.
\end{abstract}

Palavras-chave: Tecnologia da informação. Logística. Integração logística. Operadores logísticos. Redes de valor.

\begin{abstract}
The integration of logistics activities is a major challenge that involves the company's internal and external partners. Information technology (IT) plays a central role in this process since it provides infrastructure and software applications that allow the exchange of information needed to achieve such integration. The aim of this paper is propose a based IT model to analyze the external integration stages between third-party logistics providers (3PL) and the other agents of the logistics network. The analysis was based on a multiple case study conducted in four 3PLs operating in Brazil. This research identified and analyzed the technologies used in the logistics process and how they contribute to the achievement of logistic integration based on three parameters: integration and coordination of material, product, and information flow, and the establishment of partnerships between the network agents. This study revealed the existence of three levels of external integration between the 3PLs and the other agents in the network: total, partial, and lack of integration. The logistics network is considered a value network when there is total integration and the establishment of partnership between 3PLs and the other agents.
\end{abstract}

Keywords: Information technology. Logistics. Logistic integration. Third-party logistics providers (3PLs). Value network.

\section{Introdução}

O conceito de logística vem, ao longo do tempo, agregando novos elementos e tornando-se mais amplo. Segundo Ballou (2007), engloba a totalidade dos fluxos de material, produtos e informação e, portanto, abrange as ligações entre diferentes empresas da cadeia de suprimentos.

Na base da ampliação do conceito de logística, estão as possibilidades abertas pelo desenvolvimento tecnológico, com especial destaque para o uso cada vez mais intenso das Tecnologias de Informação (TI) (BALLOU, 2007; BOVET; MARTHA, 2001; CHENG, 2011; NGAI; LAI; CHENG, 2008; SCHOENHERR,
2009; SO; SUN, 2010). Por TI entendem-se as várias tecnologias convergentes e vinculadas que processam as informações que as empresas criam e utilizam (LAURINDO, 2008).

A evolução da TI resulta em diminuição no custo dos equipamentos, maior capacidade de processamento e softwares cada vez mais sofisticados, potencializados pelo desenvolvimento das telecomunicações. Tal desenvolvimento permitiu que as informações processadas e armazenadas pudessem ser transmitidas entre as empresas por meio de redes (LAUDON; LAUDON, 2007).

\footnotetext{
${ }^{1}$ Laboratório de Aprendizagem em Logística e Transporte, Faculdade de Engenharia Civil, Arquitetura e Urbanismo, Universidade Estadual de Campinas - UNICAMP, CEP 13083-852, Campinas, SP, Brasil, e-mail: branski@ fec.unicamp.br

${ }^{2}$ Departamento de Engenharia de Produção, Escola Politécnica, Universidade de São Paulo - USP, CEP 05508-900, São Paulo, SP, Brasil, e-mail: fjblau@usp.br
} 
O desenvolvimento tecnológico possibilitou a gestão da logística como um processo, integrando e coordenando as diversas atividades operacionais e priorizando a eficiência da cadeia como um todo. Um paradigma fundamental da gestão integrada da logística ressalta que o desempenho integrado produz melhores resultados que funções gerenciadas individualmente, sem coordenação entre si (BOURLAKIS; BOURLAKIS, 2006; BOWERSOX; CLOSS, 2001; CLOSS; SAVITSKIE, 2003; YUCESAN, 2007). A TI constitui, portanto, um forte pilar da gestão integrada da logística (FINK; NEUMANN, 2009; GUNASEKARAN; LAI; CHENG, 2008; SWAFFORD; GHOSH; MURTHY, 2008; VIJAYASARATHY, 2010).

No entanto, a integração é um processo complexo e que deve ser implantado de forma gradativa. Tem início dentro das organizações para, depois, se estender além dos limites da empresa, incorporando outras organizações. Os níveis mais elevados de integração pressupõem a passagem pelos estágios inferiores (VENKATRAMAN, 1994).

Nesse contexto, o objetivo do presente trabalho é propor um modelo para a classificação das fases de integração externa entre operadores e os demais agentes da rede logística a partir da identificação e análise das tecnologias de informação adotadas. A pesquisa baseou-se em um estudo de casos realizado com quatro operadores logísticos que atuam no mercado brasileiro.

O estudo de casos é um método de pesquisa que se caracteriza como uma análise detalhada e exaustiva de poucos, ou mesmo de um único objeto, fornecendo conhecimentos profundos. Utiliza geralmente dados qualitativos, coletados a partir de eventos reais, com o objetivo de explicar, explorar ou descrever fenômenos atuais inseridos em seu próprio contexto (GERRING; McDERMOTT, 2010; YIN, 2010).

Inicialmente o trabalho apresenta os conceitos básicos que fundamentaram a pesquisa: logística, logística integrada, redes de valor; e tecnologias de informação. Em seguida, descreve a metodologia utilizada e analisa os principais resultados obtidos no estudo de casos. Finalmente, propõe um modelo para classificação das fases de integração externa entre operadores e os demais agentes da rede logística.

\section{Logística, logística integrada e redes de valor}

Logística é a parte do processo da cadeia de suprimentos que planeja, estabelece e controla os fluxos e estoques de matéria-prima, produtos intermediários e acabados, serviços e informação, de forma eficiente e eficaz, desde a origem até o consumidor final. $\mathrm{O}$ fluxo de materiais compreende a movimentação e armazenagem de matéria-prima, componentes e produtos acabados entre as fontes de suprimentos, instalações e compradores da empresa, além de gerar e utilizar informações que permitem que as empresas identifiquem as necessidades do processo, e planejem e executem as operações logísticas eficientemente. Desta forma, o desempenho logístico depende da capacidade para controlar e explorar os fluxos de informação associados à movimentação de materiais e produtos (BALLOU, 2007).

A logística integrada exige integração e a coordenação dos fluxos da cadeia de suprimentos. Por meio da integração, as informações podem ser compartilhadas entre os fornecedores, fabricantes e compradores (CHENG, 2011; CHOPRA; MEINDL, 2001; GAO; QI, 2007; NGAI; LAI; CHENG, 2008). A coordenação garante o controle das atividades economicamente dispersas e a execução conjunta dos processos empresariais (CHANDRASHEKAR; SCHARY, 1999; TURBAN; RAINER; POTTER, 2003).

Contudo a coordenação exige o estabelecimento de parâmetros e regulamentações: uma ou mais empresas estabelecem diretrizes que serão seguidas pelos demais participantes. E a integração, sobretudo em seus estágios mais avançados, supõe forte relação de confiança, metas comuns e compatibilidade técnica entre os agentes da cadeia. Sendo assim, integração e coordenação pressupõem o estabelecimento de parcerias (CHOPRA; MEINDL, 2001). Entende-se por parceria o relacionamento próximo entre duas ou mais empresas, baseado na confiança mútua, com compartilhamento de informações e dos ganhos e riscos decorrentes do relacionamento. Os parceiros colaboram se há a percepção de que obterão benefícios (KUPFER; HASENCLEVER, 2002; VERDECHO et al., 2012).

Integração, coordenação e o estabelecimento de parcerias fornecem os fundamentos para a integração logística. E a gestão integrada da logística, por sua vez, constitui a base para o estabelecimento das redes de valor (SO; SUN, 2010). Bovet e Martha (2001) definem rede de valor como uma rede dinâmica de parcerias capazes de atender à demanda do comprador de forma rápida e confiável, com os agentes operando de forma colaborativa e interligados digitalmente.

\section{Tecnologias de informação na logística integrada}

Conforme mencionado, a TI constitui uma das bases da gestão integrada da logística, oferecendo infraestrutura de apoio e os diversos aplicativos que possibilitam a integração e coordenação dos agentes da cadeia, permitindo que as diferentes empresas possam operar como uma única organização. $\mathrm{O}$ Quadro 1 descreve as principais tecnologias e suas aplicações na logística integrada. 
As tecnologias foram classificadas em três categorias (BRANSKI; LAURINDO, 2009):

- Aplicativos: atendem às necessidades operacionais e estratégicas das empresas e permitem a integração com seus parceiros, garantindo a comunicação, disponibilização, acesso e intercâmbio de dados e informação com fornecedores, clientes e outros parceiros de negócio (CLOSS; SAVITISKIE, 2003; KENGPOL; TUOMINEM, 2006);

- Comunicação: equipamentos e aplicativos utilizados para coleta, armazenagem e transmissão de dados e informações; e
- Transporte ou tecnologia embarcada: oferecem suporte para as atividades envolvidas no transporte dos produtos, como roteirização, rastreamento etc.

O uso destas tecnologias contribui para a racionalização das tarefas e sincronização das atividades, resultando em maior eficiência. Seu emprego, por si só, não constitui fator de diferenciação, pois as tecnologias estão disponíveis e podem ser utilizadas por qualquer empresa. Assim, além de uma gestão eficiente dos fluxos e estoques, os operadores devem buscar um posicionamento estratégico que permita inovar em suas operações logísticas. A inovação vem do emprego da TI para o

Quadro 1. Tecnologias de Informação aplicadas na logística.

\begin{tabular}{|c|c|c|}
\hline \multicolumn{2}{|c|}{ Tecnologias } & Função \\
\hline \multicolumn{3}{|r|}{ Aplicativos } \\
\hline \multicolumn{2}{|c|}{$\begin{array}{l}\text { Enterprise Resource Planning } \\
\text { (ERP) }\end{array}$} & $\begin{array}{l}\text { Integra e coordena os processos internos das empresas, coletando os dados e } \\
\text { armazenando em um único repositório para atender a toda a organização. }\end{array}$ \\
\hline \multicolumn{2}{|c|}{$\begin{array}{l}\text { Warehouse Management System } \\
\text { (WMS) }\end{array}$} & $\begin{array}{l}\text { Apoia as atividades operacionais no processo de armazenagem. Inclui as atividades } \\
\text { de recebimento, inspeção, endereçamento, armazenagem, separação, embalagem, } \\
\text { carregamento, expedição, emissão de documentos e controle do estoque. }\end{array}$ \\
\hline \multicolumn{2}{|c|}{$\begin{array}{l}\text { Transportation Management } \\
\text { System (TMS) }\end{array}$} & $\begin{array}{l}\text { Apoia a administração do transporte de mercadorias. Inclui planejamento, } \\
\text { monitoramento e controle das atividades relativas à consolidação de cargas, } \\
\text { expedição de documentos, entregas e coletas de produtos, rastreabilidade da } \\
\text { frota, auditoria de fretes, apoio à negociação, planejamento de rotas e modais, } \\
\text { planejamento e execução de manutenção da frota. }\end{array}$ \\
\hline \multicolumn{2}{|c|}{ Business Intelligence (BI) } & $\begin{array}{l}\text { Abrange uma ampla categoria de aplicativos que organizam as informações e } \\
\text { aplicam técnicas estatísticas para gerar conhecimento e apoiar a tomada de decisões. }\end{array}$ \\
\hline \multicolumn{2}{|c|}{ Simulação } & $\begin{array}{l}\text { Aplicativos que, utilizando técnicas matemáticas, imitam o funcionamento de } \\
\text { uma operação ou processo do mundo real. }\end{array}$ \\
\hline \multicolumn{2}{|c|}{$\begin{array}{l}\text { Vendor Management Inventory } \\
\text { (VMI) }\end{array}$} & $\begin{array}{l}\text { Permite que os fornecedores controlem os estoques dos clientes, gerando } \\
\text { automaticamente pedido quando o estoque atinge um determinado nível. }\end{array}$ \\
\hline \multicolumn{3}{|r|}{ Comunicação } \\
\hline \multirow{2}{*}{$\begin{array}{l}\text { Coletores } \\
\text { de dados }\end{array}$} & $\begin{array}{l}\text { Identificação por } \\
\text { Radiofrequência } \\
\text { (RFID) }\end{array}$ & $\begin{array}{l}\text { Os dados, armazenados em etiquetas eletrônicas, são lidos e transmitidos por } \\
\text { sinais de rádio. }\end{array}$ \\
\hline & Código de Barras & $\begin{array}{l}\text { Os produtos são identificados por meio de um sistema padronizado. A leitura e } \\
\text { coleta de dados são feitas por scanner a laser. }\end{array}$ \\
\hline \multicolumn{2}{|c|}{ Terminais portáteis } & Permitem troca de dados e informações entre usuários. \\
\hline \multicolumn{2}{|c|}{$\begin{array}{l}\text { Eletronic Data Interchange } \\
\text { (EDI) }\end{array}$} & $\begin{array}{l}\text { Envio e recebimento de documentos eletrônicos padronizados entre parceiros de } \\
\text { negócios. }\end{array}$ \\
\hline \multicolumn{2}{|c|}{ Sistemas controlados por luz } & Luz indica as tarefas que devem ser realizadas pela operação. \\
\hline \multicolumn{2}{|c|}{ Sistemas controlados por voz } & Voz indica as tarefas que devem ser realizadas pela operação. \\
\hline \multicolumn{2}{|c|}{ Ferramentas $W e b$} & $\begin{array}{l}\text { Disponibilização e acesso às informações, via Intranet e Extranet, para a própria } \\
\text { empresa, seus clientes e parceiros. }\end{array}$ \\
\hline \multicolumn{3}{|r|}{ Transporte ou Tecnologia Embarcada } \\
\hline \multicolumn{2}{|c|}{ Otimização de carga } & Define a forma mais eficiente para acondicionamento da carga nos caminhões. \\
\hline \multicolumn{2}{|c|}{ Rastreamento } & $\begin{array}{l}\text { Identifica a posição de qualquer veículo ou pessoa que tenha um aparelho } \\
\text { receptor dos sinais de satélite (Sistema de Geoposicionamento - GPS). }\end{array}$ \\
\hline \multicolumn{2}{|c|}{ Roteirização } & $\begin{array}{l}\text { Instrumento de planejamento e simulação de rotas. Por meio de modelos } \\
\text { matemáticos, realiza simulações e define a rota mais eficiente. }\end{array}$ \\
\hline
\end{tabular}

Fonte: Branski e Laurindo (2009). 
desenvolvimento de processos logísticos diferenciados, permitindo a estes agentes ganhar mercados, gerar novos produtos e criar novos negócios (BOWERSOX; CLOSS; STANK, 1999; BOWERSOX; CLOSS, 2001; GRAWE, 2009).

\section{Integração das tecnologias}

No passado, as empresas possuíam vários aplicativos construídos para atender a diferentes funções, níveis da organização e processos de negócios. Estes aplicativos não eram capazes de trocar informações entre si e, portanto, não ofereciam uma visão abrangente dos processos. A fragmentação dos dados em sistemas isolados não contribuía para o desempenho das empresas (LAUDON; LAUDON, 2007).

Com os avanços da informática e das telecomunicações, as tecnologias vêm evoluindo para uma integração maior. Atualmente, por meio da TI, é possível integrar e coordenar os processos internos das empresas, como também com os de outras organizações, possibilitando assim o estabelecimento das redes (BOURLAKIS; BOURLAKIS, 2006; BOVET; MARTHA, 2001; CHENG, 2011). Neste contexto, a TI pode proporcionar vantagens competitivas para as empresas que a aplicarem de forma adequada nos seus processos (LIN, 2009).

Para Jhingran, Mattos e Pirahesh (2002), a TI apoia a integração por meio da:

- Integração da informação: ocorre quando todos os dados da organização são mantidos juntos, em um único banco de dados. Um exemplo típico, seriam os dados utilizados pelas aplicações ERP (LAURINDO; MESQUITA, 2000; XU; MA, 2008; WANGA et al., 2007);

- Integração das aplicações: aplicações com função similar ou complementar trocam dados entre si. Por exemplo, pedidos dos clientes, notificações de expedição e outras informações fluem entre o ERP, o WMS e o TMS da empresa (GUNASEKARAN; LAI; CHENG, 2008; SWAFFORD; GHOSH; MURTHY, 2008);

- Integração dos processos de negócios: coordena processos entre aplicações além dos limites da organização. Exemplos: aplicações como Supply Chain Management (SCM) trocam informações com fornecedores, clientes e outros parceiros externos das empresas, utilizando a internet ou outras redes (NGAI; LAI; CHENG, 2008; VIJAYASARATHY, 2010); e

- Integração por meio de portais: reúne, em um único ponto de entrada, aplicações que operam separadamente, usualmente utilizando intranets e extranets. Em geral, estes serviços estão centralizados em portais que oferecem, em um único lugar e com interface web, as informações da empresa (LAUDON; LAUDON, 2007).

A Figura 1 ilustra um mapa genérico das diversas tecnologias utilizadas na logística e como podem estar integradas. No ambiente interno, estão indicadas as tecnologias utilizadas para o desenvolvimento das

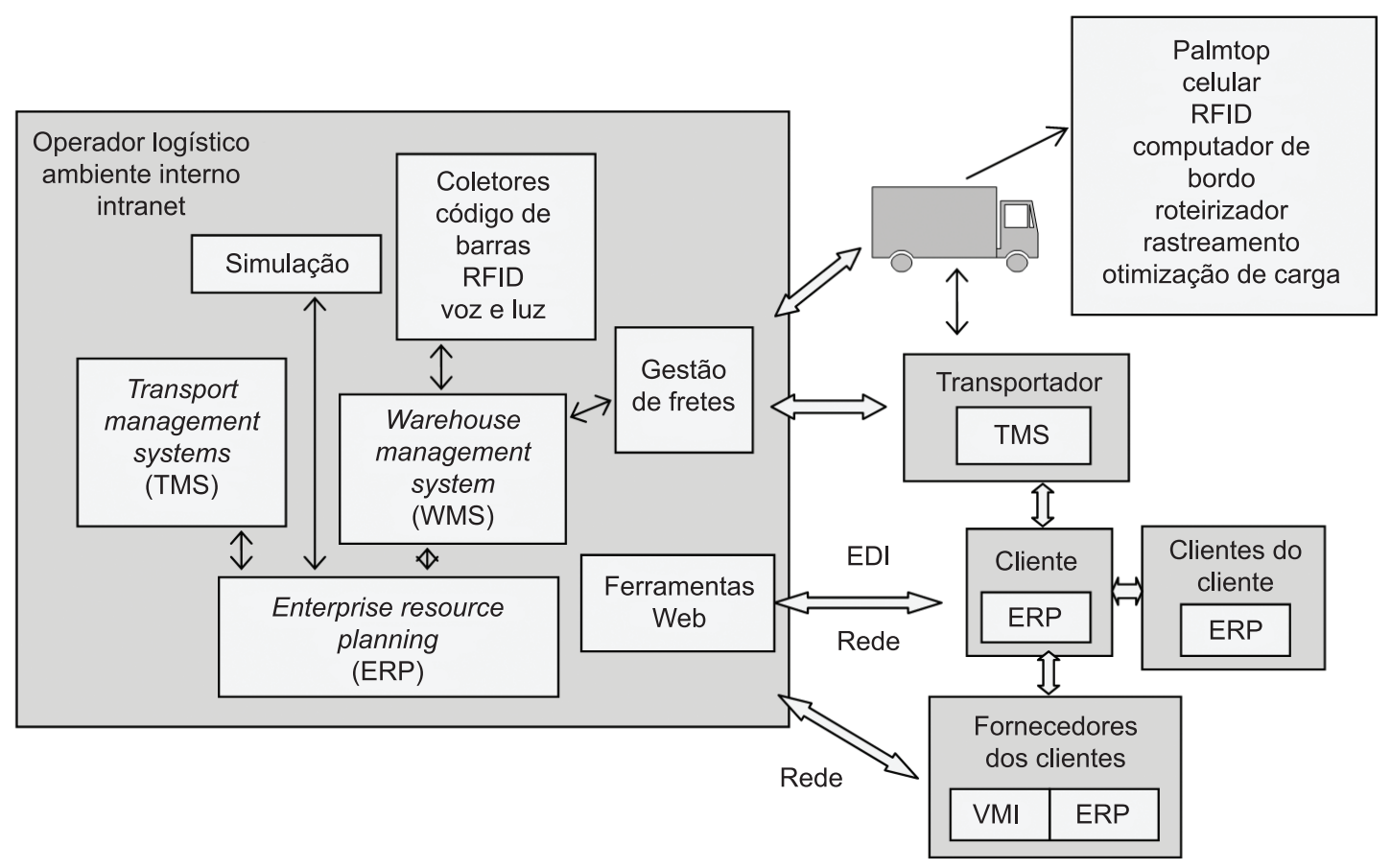

Figura 1. Tecnologia de Informação no processo logístico integrado. Fonte: Branski e Laurindo (2009). 
atividades do operador, enquanto que, no ambiente externo, são mostradas aquelas empregadas por seus parceiros ou prestadores de serviços.

Venkatraman (1994) identifica cinco estágios necessários para a obtenção da integração plena e o papel da TI em cada um deles:

- Exploração localizada: melhoria das funcionalidades de TI focadas em áreas da operação dos negócios com valor elevado. As aplicações são padronizadas e não exigem mudanças no processo de negócio;

- Integração interna: melhoria da capacidade da TI para criar um processo organizacional consistente, refletindo a (i) interconectividade técnica, operação de diferentes sistemas e aplicações por meio de uma plataforma comum de TI; e (ii) interdependência organizacional, operação conjunta dos papéis e responsabilidades da organização;

- Redesenho do processo de negócio: redesenho dos processos-chave para adequação à implantação das ferramentas de TI;

- Redesenho da rede de negócios: exploração das funcionalidades da TI para ampliação da rede; coordenação e controle. Articulação entre os agentes na rede para produzir produtos e serviços superiores; e

- Redefinição do escopo do negócio: funcionalidades da TI permitem e facilitam a redefinição do escopo das organizações (por exemplo, o que é feito dentro da empresa, e o que é obtido por meio de parceiros especiais, acordos etc.).

Os três primeiros níveis tratam do papel da TI para transformação dos negócios dentro da organização (este aspecto foi enfatizado por Swafford, Ghosh e Murthy, 2008); enquanto os dois últimos estendem-se além dos limites da empresa, incorporando outras organizações (BAILEY; FRANCIS, 2008). Exploração localizada e integração interna são níveis evolucionários porque exigem mudanças mínimas nos processos de negócios, mas são fundamentais para a exploração do potencial estratégico dos outros três níveis - redesenho do processo, redesenho da rede e redefinição do escopo do negócio - estes sim revolucionários, já que exigem alterações nas próprias organizações.

\section{Método}

A abordagem metodológica mais adequada para atender aos objetivos da pesquisa foi o estudo de casos múltiplos. Estudo de caso é uma pesquisa qualitativa que tem como objetivo realizar uma análise profunda do fenômeno visando obter conhecimento detalhado. Deve estar baseado em múltiplas fontes de evidências, tais como observação direta, entrevistas, documentos etc.; e deve utilizar procedimentos, métodos e ferramentas científicas para a coleta de dados e informações, assegurando assim a veracidade dos fatos (YIN, 2010).

Estudos de casos podem ser descritivos ou analíticos. Nos descritivos o pesquisador descreve os eventos ocorridos enquanto, nos analíticos, testa hipóteses ou estabelece associações, correlações ou inferências entre os eventos. Os dados obtidos nos estudos descritivos fornecem profundidade e riqueza de detalhes e servem como base para formulação de hipóteses e modelos que podem, posteriormente, ser confirmados ou rejeitados por estudos analíticos. Assim, estudos descritivos podem ajudar no desenvolvimento de novas ideias e de teorias apoiadas na prática (BROWN, 2010).

Os estudos de casos são adequados para identificar e analisar aplicações de TI porque, segundo Yin (2010), permitem compreender as decisões tomadas pelas empresas, suas formas de implantação e os resultados obtidos, além de investigar o como e o porquê das questões. Ainda, no caso particular da pesquisa, optou-se por estudo de casos descritivos, dado que o objetivo do trabalho é a proposição de um modelo para identificação e análise das fases de integração externa entre operadores e os demais agentes da rede logística.

As etapas desenvolvidas no trabalho estão representadas na Figura 2:

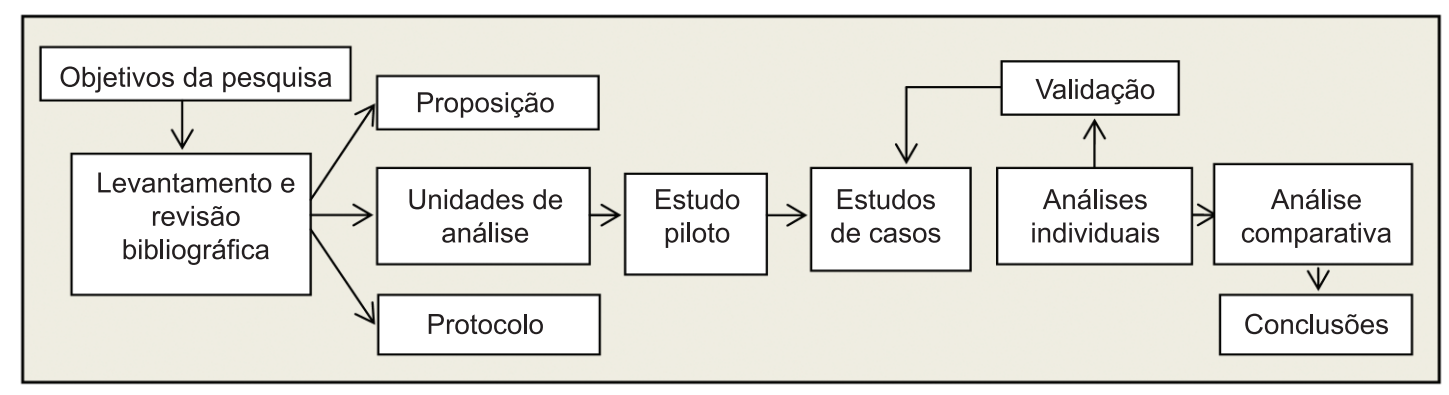

Figura 2. Etapas do desenvolvimento do estudo de casos. Fonte: adaptado de Yin (2010). 
A primeira etapa foi a definição do objetivo da pesquisa. Em seguida, foi realizada revisão bibliográfica que permitiu estabelecer os fundamentos da pesquisa e os elementos a serem investigados (BRANSKI; AURELLANO; LIMA JUNIOR, 2010; YIN, 2010).

Partindo da premissa de que: para compreender como as tecnologias são utilizadas no processo logístico é preciso mapear os fluxos de materiais, produtos e informação entre os agentes da cadeia e identificar as tecnologias utilizadas nas diversas atividades, o estudo mapeou o processo logístico dos operadores e identificou as tecnologias utilizadas em suas atividades.

Em seguida, a pesquisa investigou as seguintes proposições:

Proposição 1 (Pl): As tecnologias de informação estão na base da gestão integrada da logística. Gestão integrada da logística pressupõe integração e coordenação dos fluxos e estoques de materiais, produtos e informação e o estabelecimento de parcerias entre diferentes agentes.

Proposição 2 (P2): A gestão integrada da logística está na base do estabelecimento das redes de valor. Para que a gestão integrada da logística possa constituir uma rede de valor, os fluxos e estoques de materiais, produtos, serviços e informação devem ser administrados como um processo contínuo entre as empresas, ou seja, os agentes operam de forma colaborativa e ocorre o compartilhamento total das informações. Parcerias fortes e uso intensivo de tecnologia fornecem a base para o estabelecimento destas redes.

A Figura 3, a seguir, indica as proposições e as respectivas referências analisadas para a consolidação da estrutura de análise.

De acordo com o constructo adotado, a análise do papel das tecnologias na integração logística deve estar baseada em três parâmetros: integração e coordenação dos fluxos de materiais, produtos e informação; e o estabelecimento de parcerias.
A etapa seguinte foi a definição das unidades de análise. Foram selecionados, de forma intencional, quatro operadores com diferentes características: dois operadores têm alcance mundial e os demais atuam exclusivamente no Brasil, operam em diversos setores podendo ser classificados desde especialistas a generalistas e, em conjunto, permitem uma visão geral da cadeia de suprimentos.

Antes da coleta de dados, foi feito um estudo piloto com um dos operadores logísticos, selecionado pela facilidade de acesso ao seu diretor operacional. $\mathrm{O}$ estudo piloto permitiu uma primeira aproximação com o objeto a ser estudado a fim de testar os procedimentos de pesquisa e efetuar os ajustes necessários para melhor condução dos demais casos.

Posteriormente, os dados foram coletados por meio de entrevistas semiestruturadas, além de consulta ao site da empresa na internet e a outras publicações especializadas. Foi elaborado, para cada estudo de caso, relatórios com estruturas semelhantes. As evidências foram apresentadas de forma neutra, apenas descrevendo o que foi coletado nas entrevistas.

Algumas dúvidas, ou mesmo novos questionamentos, emergentes no momento da elaboração do relatório, foram solucionados contatando, por telefone ou e-mail, os executivos entrevistados. Os relatórios foram enviados para os entrevistados para revisão, para corroborar as evidências e os fatos apresentados e assim aumentar a validade do estudo. No caso da pesquisa, não houve discordância dos entrevistados quanto ao conteúdo dos relatórios e alguns novos elementos foram acrescentados, possibilitando a análise individual de cada caso. Por fim, foi realizada uma análise comparativa entre os casos (análise cruzada).

\section{Estudo de casos múltiplos}

A pesquisa foi realizada com quatro operadores logísticos com atuação no mercado brasileiro.

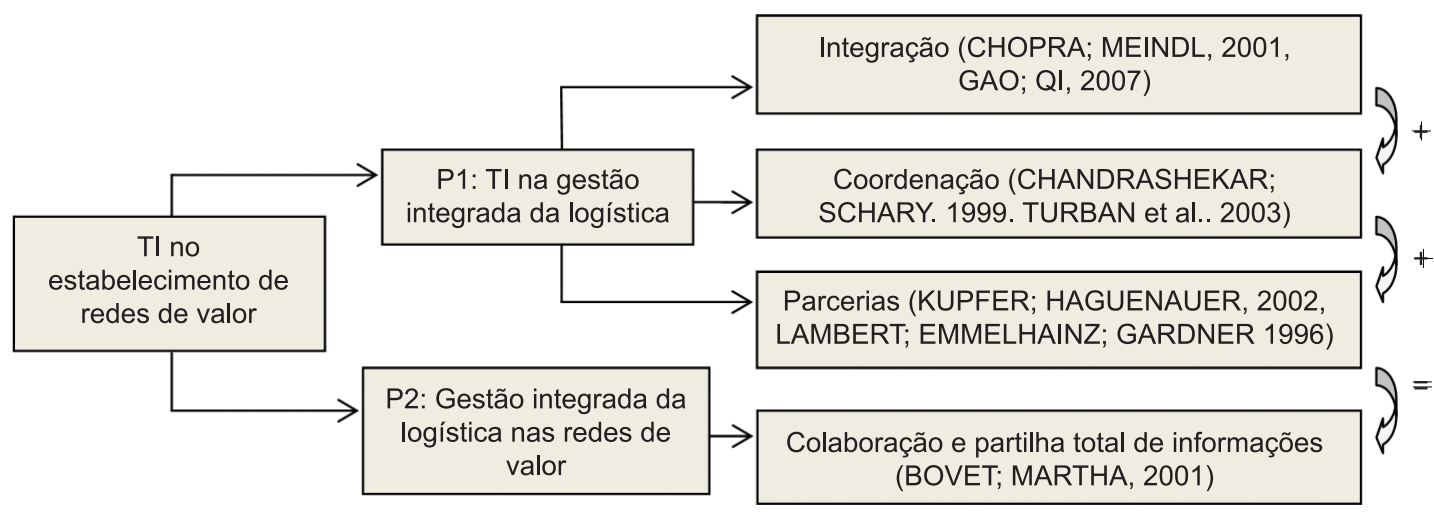

Figura 3. Proposições e autores analisados. Fonte: Branski (2008). 
- Operador logístico 1 (OL 1): presta serviço completo na terceirização logística dos processos de importação e exportação;

- Operador logístico 2 (OL 2): presta serviço em distribuição e operações logísticas exclusivamente para uma rede fast-food;

- Operador logístico 3 (OL 3): atua na armazenagem e na gestão do transporte e da cadeia de suprimentos especialmente nos setores automotivo, eletroeletrônico e de consumo; e

- Operador logístico 4 (OL 4): atua na armazenagem e na gestão do transporte e da cadeia de suprimentos em empresas de todos os tamanhos e de setores variados.

OL 1 atua na logística internacional. OL 2, por atender a um único cliente, é bastante especializado. Os operadores logísticos 3 e 4 têm perfis semelhantes, mas enquanto OL 3 está focado em poucos setores, OL 4 é mais generalista. Os quatro operadores estudados possibilitaram uma visão ampla já que atendem diferentes setores, apresentam diferentes características, desenvolvem diferentes atividades com diferentes posicionamentos estratégicos.

O Quadro 2 mostra as características de cada uma das empresas analisadas.

Todas as entrevistas foram realizadas com profissionais especializados da área de TI e com longo tempo de atuação no mercado. Três deles atuam em cargos de direção (OL 1, OL 2 e OL 3). Com exceção do OL 4, todos os demais entrevistados já trabalham há um tempo significativo nas empresas e, portanto, foram capazes de recontar suas histórias e o desenvolvimento da TI.

Com relação aos operadores:

- Quanto à origem, uma empresa é nacional (OL 1) e as demais são multinacionais americanas (OL 2, OL 3 e OL 4). No caso de OL 4, foi adquirida posteriormente por um importante operador logístico alemão, que manteve a marca para os serviços logísticos;

- Quanto ao escopo geográfico e o tempo de atuação, todos atuam no mercado brasileiro e dois deles (OL 1 e OL 4) têm atuação global. OL 2 é o operador que atua há mais tempo no Brasil (cerca de 30 anos), seguido de OL 1 (23 anos). Os demais operam há cerca de dez anos;

- Quanto ao número de funcionários, OL 1 e OL 2 mantêm cerca de 450 empregados. Os outros três operadores apresentam um número significativamente superior: respectivamente, 1600, 2000 e 2700;

- OL 4 é o que apresenta o maior número de funcionários atuando na área de tecnologia de informação (50 pessoas). Este número é significativamente maior que dos outros operadores, mesmo quando comparado ao total de empregados;

- A TI ocupa uma posição de destaque na hierarquia de todas as empresas. Em três delas (OL 2, OL 3 e OL 4), está subordinada diretamente à presidência e, nas outras duas (OL 1 e OL 5), à diretoria;

- Quanto às atividades de origem, os operadores pesquisados são bastante diversificados. OL 1 iniciou suas atividades como despachante aduaneiro, OL 2 como atacadista no setor de papel para restaurantes, OL 3 como prestador de serviços logísticos, e OL 4 como correio expresso aéreo.

Finalmente, quanto à infraestrutura de rede dos operadores:

- OL 1 não dispõe de armazéns para o desenvolvimento de suas atividades. Já os armazéns e centros de apoio de OL 2 foram planejados para atender seu único cliente, a rede fast-food. Os demais operadores possuem diversos CDs localizados de forma a atender às necessidades de seus negócios; e

- Com relação à frota terrestre, somente OL 1 e OL 2 possuem caminhões próprios, sendo que, no caso de OL 2, foram especialmente fabricados para atender seu cliente. Os outros dois operadores (OL 3 e OL 4) utilizam frota de terceiros. OL 3 mantém uma relação bastante próxima com estes prestadores de serviço, inclusive disponibilizando as tecnologias embarcadas nos caminhões.

O Quadro 3 mapeia os agentes das redes logísticas: os operadores estabelecem os elos entre os clientes, fornecedores, prestadores de serviço etc.

- Quanto aos clientes, OL 2 possui um único cliente, sendo, portanto, bastante especializado. OL 3 opera em poucos setores. Os outros dois operadores, OL 1 e OL 4, são mais diversificados atendendo clientes de vários segmentos;

- Quanto aos fornecedores, OL 1 utiliza os serviços dos armadores, companhias aéreas, transportadoras, armazéns e, eventualmente, outros operadores logísticos. OL 2 não tem fornecedores próprios. Seu trabalho é estabelecer a ligação entre os diversos fornecedores da rede fast food e os pontos de venda. Os fornecedores de OL 3 e OL 4 são as empresas transportadoras; e

- Finalmente, quanto aos parceiros, OL 1 mantém forte vínculo com um grande operador logístico com atuação global "A"; OL 2, com seu cliente, 
Quadro 2. Caracterização dos operadores logísticos.

\begin{tabular}{|c|c|c|c|c|}
\hline Operador Logístico & OL 1 & OL 2 & OL 3 & OL 4 \\
\hline Origem & Nacional & Multinacional & Multinacional & Multinacional \\
\hline Ano de fundação & 1985 & $\begin{array}{c}1955 \\
\text { No Brasil desde } 1979\end{array}$ & No Brasil desde 1998 & $\begin{array}{c}1969 \\
\text { No Brasil desde } 2002\end{array}$ \\
\hline $\begin{array}{c}\text { Número de } \\
\text { funcionários no } \\
\text { Brasil }\end{array}$ & 450 & 420 & 1600 & 2000 \\
\hline $\begin{array}{c}\text { Funcionários da área } \\
\text { de TI }\end{array}$ & 7 & 9 & 12 & 50 \\
\hline TI na hierarquia & $\begin{array}{c}\text { Subordinada à } \\
\text { diretoria de operação }\end{array}$ & $\begin{array}{c}\text { Subordinada à } \\
\text { presidência }\end{array}$ & $\begin{array}{c}\text { Subordinada à } \\
\text { presidência }\end{array}$ & $\begin{array}{c}\text { Subordinada à } \\
\text { presidência }\end{array}$ \\
\hline Atividade de origem & $\begin{array}{l}\text { Despachante } \\
\text { aduaneiro }\end{array}$ & $\begin{array}{c}\text { Fornecedora de } \\
\text { produtos de papel } \\
\text { para restaurantes }\end{array}$ & $\begin{array}{c}\text { Prestador de serviços } \\
\text { logísticos }\end{array}$ & $\begin{array}{l}\text { Correio expresso } \\
\text { aéreo }\end{array}$ \\
\hline Escopo geográfico & Alcance mundial & $\begin{array}{c}\text { Brasil e outros países } \\
\text { da América Latina e } \\
\text { Central }\end{array}$ & Brasil & Alcance mundial \\
\hline Área de atuação & $\begin{array}{l}\text { Logística } \\
\text { internacional }\end{array}$ & $\begin{array}{l}\text { Distribuidor logístico } \\
\text { de produtos para rede } \\
\text { fast-food }\end{array}$ & $\begin{array}{c}\text { Gestão da cadeia } \\
\text { de suprimentos e } \\
\text { serviços } \\
\text { logísticos } \\
\end{array}$ & $\begin{array}{l}\text { Gestão da cadeia } \\
\text { de suprimentos e } \\
\text { serviços logísticos }\end{array}$ \\
\hline Cargo do entrevistado & Diretor de operações & Diretor de TI & Diretor de TI & $\begin{array}{l}\text { Transportation } \\
\text { Operation Leader } \\
\text { (TI) }\end{array}$ \\
\hline Formação & $\begin{array}{l}\text { Engenheiro } \\
\text { eletrônico }\end{array}$ & Analista de sistema & Analista de sistema & Administrador \\
\hline Experiência & 20 anos & 27 anos & 29 anos & 22 anos \\
\hline Tempo no empresa & 9 anos & 13 anos & 7 anos & 3 anos \\
\hline \multicolumn{5}{|c|}{ Estrutura de rede } \\
\hline Armazéns ou CDs & $1 \mathrm{CD}$ de apoio & $\begin{array}{c}3 \text { CDs e } 2 \text { Centros de } \\
\text { Apoio }\end{array}$ & $11 \mathrm{CDs}$ & $25 \mathrm{CDs}$ \\
\hline Frota terrestre & 42 caminhões & 100 caminhões & Terceirizada & $\begin{array}{c}\text { Terceirizada } \\
100 \text { empresas } \\
\text { transportadoras }\end{array}$ \\
\hline Frota aérea & - & - & - & $\begin{array}{c}4 \text { Cia. Aéreas } \\
\text { No Brasil opera com } \\
\text { aviões próprios e de } \\
\text { terceiros }\end{array}$ \\
\hline Frota marítima & - & - & - & Terceirizada \\
\hline
\end{tabular}

Fonte: Branski (2008).

a rede fast-food; OL 3, com as empresas de transporte; e OL 4 não mantém parcerias.

A pesquisa identificou as tecnologias adotadas pelos operadores no processo logístico, sintetizadas no Quadro 4.

- OL 2 e OL 3 possuem sistemas Sistema de Gestão Empresarial (ERP), adquiridos no mercado. No caso de OL 2 e OL 3, os sistemas foram, ao longo do tempo, customizados para atender às necessidades das empresas;

- Com exceção de OL 1, os operadores possuem Sistemas de Gestão de Armazéns (WMS), exceto OL 1. No caso de OL 2, somente parte de um WMS adquirido no mercado é utilizado. Já nos OL 3 e OL 4, o WMS foi especialmente desenvolvido por empresas de software para atender a suas necessidades, sendo que OL 4 utiliza dois WMS: um deles adotado pela empresa em todo o mundo e outro herdado de uma das empresas adquiridas pelo grupo;

- Somente OL 3 e OL 4 utilizam Sistemas de Gestão do Transporte. No caso de OL 3, o sistema foi adquirido no mercado. Já o sistema de OL 4 foi desenvolvido internamente para que pudesse se adequar ao WMS adotado mundialmente pela matriz; 
Quadro 3. Elementos da rede logística.

\begin{tabular}{|c|c|c|c|c|}
\hline Agentes & OL 1 & OL 2 & OL 3 & OL 4 \\
\hline Clientes & $\begin{array}{l}\text { Supermercados, indústria } \\
\text { farmacêutica, cosméticos, } \\
\text { autopeças, siderurgia, } \\
\text { eletroeletrônico e } \\
\text { informática. }\end{array}$ & Rede fast-food & $\begin{array}{l}\text { Automotivos, } \\
\text { eletroeletrônico } \\
\text { e varejo. }\end{array}$ & $\begin{array}{c}\text { Empresas de todos } \\
\text { os tamanhos e com } \\
\text { necessidades variadas. No } \\
\text { Brasil, atende a empresas } \\
\text { do setor automotivo, } \\
\text { químico e industrial; } \\
\text { consumo e varejo; saúde e } \\
\text { tecnologia. }\end{array}$ \\
\hline Fornecedores & $\begin{array}{l}\text { Outros operadores } \\
\text { logísticos, armadores, cia. } \\
\text { aéreas, agentes de carga, } \\
\text { despachantes aduaneiros, } \\
\text { transportadoras, armazéns, } \\
\text { Receita Federal e Banco } \\
\text { Central. }\end{array}$ & $\begin{array}{l}\text { Fabricantes de produtos } \\
\text { à base de carne, pães, } \\
\text { hortifrutigranjeiros, } \\
\text { batatas fritas, } \\
\text { leite e derivados, } \\
\text { refrigerantes, e outros. }\end{array}$ & Transportadoras & Transportadoras \\
\hline Parceiros & Operador logístico "A" & Rede fast-food & Transportadoras & - \\
\hline
\end{tabular}

Fonte: Branski (2008).

- Quanto à tecnologia embarcada nos caminhões, no caso de OL 4, como opera com transportadoras com níveis variados de desenvolvimento tecnológico, nem todas possuem estes sistemas. Mas, nos demais operadores, todos os caminhões são equipados com GPS para rastreamento e roteirização. Cada operador adota um tipo de receptor: OL 2 utiliza Palm-top, mas está mudando para tecnologia Bluetooth; e OL 3, computador de bordo. No caso particular de OL 3, como tem grande preocupação com a segurança, todos os caminhões são equipados com um software para controle e rastreamento de suas cargas;

- Quanto aos aplicativos desenvolvidos internamente, OL 1 utiliza um sistema de apoio à exportação e importação; OL 2, o "Sistema Órbita", integrado ao seu Sistema de Gestão Empresarial (ERP) e que é o diferencial de seu negócio; e OL 4, o "Sistema Fiscal Logístico", que executa a parte fiscal e de documentação substituindo o sistema ERP;

- Quanto aos aplicativos de Business Intelligence, estes softwares permitem, a partir de um grande volume de dados, extrair informações e transformá-las em conhecimento. Entre os operadores investigados, somente OL 2 utiliza este aplicativo; e

- Quanto aos sistemas em implantação, OL 2 está desenvolvendo um módulo VMI com informações para seus fornecedores, OL 3 está implantando um software para consolidação de cargas adquirido no mercado, e OL 4 está buscando no mercado um novo TMS.
Depois do levantamento das tecnologias adotadas, foram investigados, em cada operador, três elementos: (i) integração entre o operador logístico e os agentes; (ii) coordenação dos fluxos de materiais, produtos e informação e o agente coordenador; e (iii) existência de parceria. Finalmente, buscou-se mapear as redes de valor, compartilhamento de informação e colaboração total entre os agentes, tendo como base o uso intensivo da TI e o estabelecimento de parcerias fortes. $\mathrm{O}$ Quadro 5 resume os principais resultados.

- OL 1 está integrado a alguns clientes - o sistema utilizado é capaz de trocar informação diretamente com o ERP dos clientes - e ao operador logístico "A" - acessa as informações diretamente no banco de dados de "A", assim como "A" acessa os seus sistemas, além da troca de documentos por meio de EDI. OL 1 não está integrado a seus fornecedores, com exceção dos armadores e da Receita Federal, na qual pode, graças aos sistemas desenvolvidos por estes agentes, disponibilizar e captar informações diretamente nos bancos de dados. A coordenação é realizada pelo operador logístico "A" que permite a OL 1 executar suas atividades em bases mundiais. Finalmente, a parceria com "A" está fortemente estabelecida, já que cada empresa vê a outra como extensão de seu negócio;

- O sistema desenvolvido por OL 2 garante integração com seu cliente - a rede fast-food -, com os clientes de seu cliente - as lojas da rede - que colocam seus pedidos diretamente nos servidores de OL 2, e com os caminhões - as informações são carregadas e descarregadas 
dos palm-tops dos motoristas diretamente no sistema de OL 2. A integração com os fornecedores é menor: a troca de informação é realizada por $e$-mail e não há acesso direto dos fornecedores às informações de OL 2. Com relação à coordenação, OL 2 é responsável pela sincronização dos fluxos entre os parceiros, estabelecendo parâmetros e regulamentações que devem ser seguidos pelos agentes, tais como codificação de materiais e produtos.

Quadro 4. Tecnologia da informação no processo logístico.

\begin{tabular}{|c|c|c|c|c|}
\hline TI & OL 1 & OL 2 & OL 3 & OL 4 \\
\hline ERP & - & $\begin{array}{c}\text { Atende a tarefas } \\
\text { básicas. Foi sendo } \\
\text { complementado pelos } \\
\text { módulos do "Sistema } \\
\text { Órbita" }\end{array}$ & $\begin{array}{l}\text { Focado no } \\
\text { gerenciamento da } \\
\text { parte documental }\end{array}$ & - \\
\hline WMS & - & $\begin{array}{l}\text { Utiliza partes do } \\
\text { WMS. } \\
\text { Adquirido no mercado }\end{array}$ & $\begin{array}{c}\text { Desenvolvido por } \\
\text { uma Software House } \\
\text { para atender a suas } \\
\text { necessidades }\end{array}$ & $\begin{array}{l}\text { WMS herdado de uma } \\
\text { das empresas que foi } \\
\text { adquirida pelo grupo } \\
\text { e é ainda utilizado } \\
\text { por cerca de } 30 \% \text { dos } \\
\text { clientes. } \\
\text { WMS desenvolvido } \\
\text { por uma Software } \\
\text { House italiana }\end{array}$ \\
\hline TMS & - & - & Adquirido no mercado & $\begin{array}{l}\text { Desenvolvido } \\
\text { internamente }\end{array}$ \\
\hline $\begin{array}{c}\text { Tecnologia } \\
\text { embarcada nos } \\
\text { caminhões }\end{array}$ & $\begin{array}{c}\text { Sistema de } \\
\text { Posicionamento } \\
\text { Global (GPS) } \\
\text { para rastreamento e } \\
\text { roteirização }\end{array}$ & $\begin{array}{c}\text { Computador de } \\
\text { bordo que registra os } \\
\text { movimentos físicos do } \\
\text { caminhão } \\
\text { Palm-top equipado } \\
\text { com software de } \\
\text { gestão de rota (GPS) }\end{array}$ & $\begin{array}{l}\text { Computador de } \\
\text { bordo que controla } \\
\text { a localização do } \\
\text { caminhão (GPS) } \\
\text { Computador que } \\
\text { protege a carga, } \\
\text { equipado com o } \\
\text { software e-cargo } \\
\text { de controle e } \\
\text { rastreamento de cargas } \\
\text { e entregas } \\
\end{array}$ & $\begin{array}{c}\text { A cargo das } \\
\text { transportadoras }\end{array}$ \\
\hline $\begin{array}{l}\text { Aplicativos } \\
\text { desenvolvidos } \\
\text { internamente }\end{array}$ & $\begin{array}{c}\text { Composto de duas } \\
\text { partes: exportação } \\
\text { e importação. Cada } \\
\text { parte tem vários } \\
\text { módulos que apoiam o } \\
\text { desenvolvimento das } \\
\text { atividades }\end{array}$ & $\begin{array}{l}\text { Sistema Órbita: } \\
\text { possui módulos como } \\
\text { "pedido via web" } \\
\text { e "gerenciador de } \\
\text { campanha" }\end{array}$ & - & $\begin{array}{c}\text { Sistema Fiscal } \\
\text { Logístico (SFL) que } \\
\text { executa a parte fiscal }\end{array}$ \\
\hline $\begin{array}{c}\text { Business } \\
\text { Intelligence }(B I)\end{array}$ & $\begin{array}{c}\text { Desenvolveu } \\
\text { internamente algumas } \\
\text { funcionalidades } \\
\text { do sistema que } \\
\text { permitem analisar } \\
\text { e disponibilizar os } \\
\text { resultados para o } \\
\text { gerenciamento. }\end{array}$ & $\begin{array}{c}\text { Trata as informações } \\
\text { coletadas na entrega } \\
\text { e produz relatórios } \\
\text { estatísticos. } \\
\text { Desenvolvido } \\
\text { internamente }\end{array}$ & - & - \\
\hline Em implantação & & $\begin{array}{l}\text { Módulo VMI do } \\
\text { Sistema Órbita com } \\
\text { informação sobre os } \\
\text { estoques, a demanda } \\
\text { e o consumo efetivo } \\
\text { nas lojas para } \\
\text { fornecedores }\end{array}$ & $\begin{array}{c}\text { Software para } \\
\text { otimizaçao das cargas. } \\
\text { Adquirido no mercado }\end{array}$ & $\begin{array}{l}\text { Pesquisando no } \\
\text { mercado para adquirir } \\
\text { um novo TMS }\end{array}$ \\
\hline
\end{tabular}

Fonte: Branski (2008). 
Finalmente, quanto às parcerias, elas estão no fundamento de operação desta rede: OL 2, assim como grande parte dos fornecedores, atende exclusivamente à rede fast-food e está intrinsecamente ligada à ela;

- OL 3 mantém integração com seus clientes e com as transportadoras, acessando e permitindo acesso aos bancos de dados e trocando documentos via EDI. Com relação à coordenação, OL 3 não é responsável pela sincronização dos fluxos entre os agentes da cadeia, uma vez que somente recebe o comunicado de venda e realiza a entrega. $\mathrm{O}$ estabelecimento dos parâmetros e regulamentações que devem ser seguidos pelos agentes, tais como codificação de materiais e produtos, é determinado por seus clientes. Finalmente, seus principais parceiros são as empresas de transporte, sendo que toda a tecnologia embarcada nos caminhões é disponibilizada pelo OL 3, obedecendo, portanto, aos seus padrões; e

- OL 4 tem capacidade para estabelecer integração com clientes e fornecedores. O operador é capaz de trocar informações das mais variadas formas: por meio de EDI sobre redes privadas (VPN), e-mail, FTP, telefone etc.; mas procura adequar-se ao desenvolvimento tecnológico e interesse de cada agente. No nível mais elevado, o fluxo de informação é estabelecido entre o ERP dos clientes e o sistema de OL 4 e todas as informações ficam disponíveis para os clientes no seu portal na internet. Com relação à coordenação, OL 4 não estabelece a sincronização dos fluxos entre seus clientes e os clientes de seus clientes: apenas recebe o comunicado da venda e realiza as entregas. Os parâmetros e regulamentações que devem ser seguidos pelos agentes, tais como codificação de materiais e produtos, são estabelecidos pelos clientes. Finalmente, não foram identificadas parcerias do operador com nenhum agente da rede.

Assim, quanto à integração externa, as tecnologias de informação possibilitam a conexão dos agentes por meio do estabelecimento de links diretos entre computadores, pela troca eletrônica de dados (EDI) ou, ainda, pelo acesso e disponibilização das informações por meio de portais com interface web. Os quatro operadores estão integrados aos seus clientes e, com exceção de OL 1 , às transportadoras. Além disto, OL 2 está integrado aos clientes do cliente (lojas da rede) e OL 1 ao seu parceiro, operador logístico A. Quanto à coordenação, OL 2 é o único operador que coordena o processo logístico, estabelecendo parâmetros e regulamentações. No caso de OL 1, a coordenação é realizada por seu parceiro logístico "A" e, em OL 3 e OL 4, pelos clientes. Quanto ao estabelecimento de parcerias, pode-se observar sua ocorrência em três dos casos estudados: OL 1 mantém parceria de longo prazo com outro operador, OL 2 com o cliente, e OL 3 com as transportadoras, enquanto OL 4 não mantém parceria com nenhum agente da sua rede logística.

Quadro 5. Principais Resultados dos Estudos de Casos.

\begin{tabular}{|c|c|c|c|c|c|c|c|}
\hline Objetivos & Proposições & $\begin{array}{l}\text { Elementos de } \\
\text { análise }\end{array}$ & OL 1 & OL 2 & OL 3 & OL 4 & Conclusão \\
\hline \multirow{4}{*}{$\begin{array}{c}\text { Analisar papel } \\
\text { da TI nas redes } \\
\text { de valor }\end{array}$} & \multirow{3}{*}{$\begin{array}{c}\text { A TI está } \\
\text { na base } \\
\text { da gestão } \\
\text { integrada da } \\
\text { logística }\end{array}$} & Integração & $\begin{array}{c}\text { Integrado } \\
\text { aos clientes } \\
\text { e ao } \\
\text { operador } \\
\text { "A" }\end{array}$ & $\begin{array}{c}\text { Integrado ao } \\
\text { cliente, clientes } \\
\text { do cliente e } \\
\text { transportadoras. } \\
\text { Troca de } \\
\text { informação } \\
\text { via } e \text {-mail com } \\
\text { fornecedores }\end{array}$ & $\begin{array}{c}\text { Integrado } \\
\text { aos clientes e } \\
\text { transportadoras }\end{array}$ & $\begin{array}{c}\text { Integrado } \\
\text { aos clientes e } \\
\text { transportadoras }\end{array}$ & \multirow{3}{*}{$\begin{array}{c}\text { Integrados } \\
\text { aos clientes e, } \\
\text { três deles, às } \\
\text { transportadoras; } \\
\text { coordenação } \\
\text { do cliente ou } \\
\text { do operador } \\
\text { e parcerias } \\
\text { com diferentes } \\
\text { agentes }\end{array}$} \\
\hline & & Coordenação & $\begin{array}{l}\text { Operador } \\
\text { Logístico } \\
\text { "A" }\end{array}$ & OL 2 & Clientes & Clientes & \\
\hline & & Parcerias & $\begin{array}{l}\text { Operador } \\
\text { Logístico } \\
\text { "A" }\end{array}$ & Rede fast-food & Transportadoras & - & \\
\hline & $\begin{array}{c}\text { A gestão } \\
\text { integrada } \\
\text { da logística } \\
\text { está na base } \\
\text { das redes de } \\
\text { valor }\end{array}$ & $\begin{array}{c}\text { Colaboração e } \\
\text { compartilhamento } \\
\text { total de } \\
\text { informações }\end{array}$ & $\begin{array}{l}\text { Ocorre em } \\
\text { segmentos }\end{array}$ & $\begin{array}{l}\text { Ocorre em } \\
\text { segmentos. } \\
\text { Caso mais } \\
\text { próximo de } \\
\text { rede de valor }\end{array}$ & $\begin{array}{l}\text { Ocorre em } \\
\text { segmentos }\end{array}$ & $\begin{array}{l}\text { Ocorre em } \\
\text { segmentos }\end{array}$ & $\begin{array}{l}\text { Identificados } \\
\text { segmentos de } \\
\text { rede de valor }\end{array}$ \\
\hline
\end{tabular}


Finalmente, quanto às redes de valor, elas exigem que os fluxos e estoque de bens físicos sejam administrados como um processo contínuo entre as empresas, com os agentes operando de forma colaborativa e compartilhando as informações. Assim, parcerias fortes e uso intensivo de tecnologia fornecem a base para o estabelecimento destas redes. No caso da pesquisa, foi possível observar o compartilhamento total de informações e estabelecimento de parcerias entre os operadores e alguns dos agentes constituindo, portanto, segmentos de rede de valor.

\section{Modelo de análise das fases de integração externa dos operadores com outros agentes da rede}

A partir dos casos estudados foi possível identificar a ocorrência de três fases na integração entre os operadores logísticos e os demais agentes da rede: plena, parcial e inexistente. Foi denominada integração plena quando ocorre compartilhamento total de informações, com os agentes acessando e permitindo acesso aos seus bancos de dados; parcial quando somente um dos agentes acessa e atualiza as informações no banco de dados do outro agente; e, finalmente, inexistente, quando não há troca de informação por meio eletrônico. A Figura 4, a seguir, indica as fases de integração observadas no estudo de casos.

No caso da pesquisa, ocorreu compartilhamento total de informações entre o OL 1 e o operador logístico "A" e, também, com seus clientes, e parcial com os armadores e a Receita Federal; houve compartilhamento total das informações de OL 2 com seu único cliente, com os clientes do cliente e com as transportadoras, e parcial com fornecedores; houve compartilhamento total das informações entre OL 3, seus clientes e as transportadoras; e, finalmente, ocorreu compartilhamento total das informações entre OL 4, seus clientes e as transportadoras. Assim, os operadores estudados compartilham de forma plena as informações, acessando e permitindo acesso às bases de dados, com seus clientes e, com exceção de OL 1 , com as transportadoras. Com os demais agentes, o compartilhamento é parcial, com o operador acessando os bancos de dados destes agentes.

A partir da identificação das fases da integração e dos agentes da rede logística, foi elaborado um modelo que representa os níveis da integração externa entre os agentes e as parcerias estabelecidas identificando, assim, as redes de valor (Figura 5).

No eixo horizontal, foram representados os agentes da rede logística (clientes, fornecedores dos clientes e clientes dos clientes) e os prestadores de serviços do operador (transportadoras, outros operadores logísticos, desenvolvedores de softwares, despachantes aduaneiros etc.); e, no eixo vertical, os três níveis de integração externa identificados: plena, parcial e inexistente. Os círculos escuros indicam a existência de parcerias entre o operador e os agentes da rede. Operadores com elevado grau de integração e parcerias

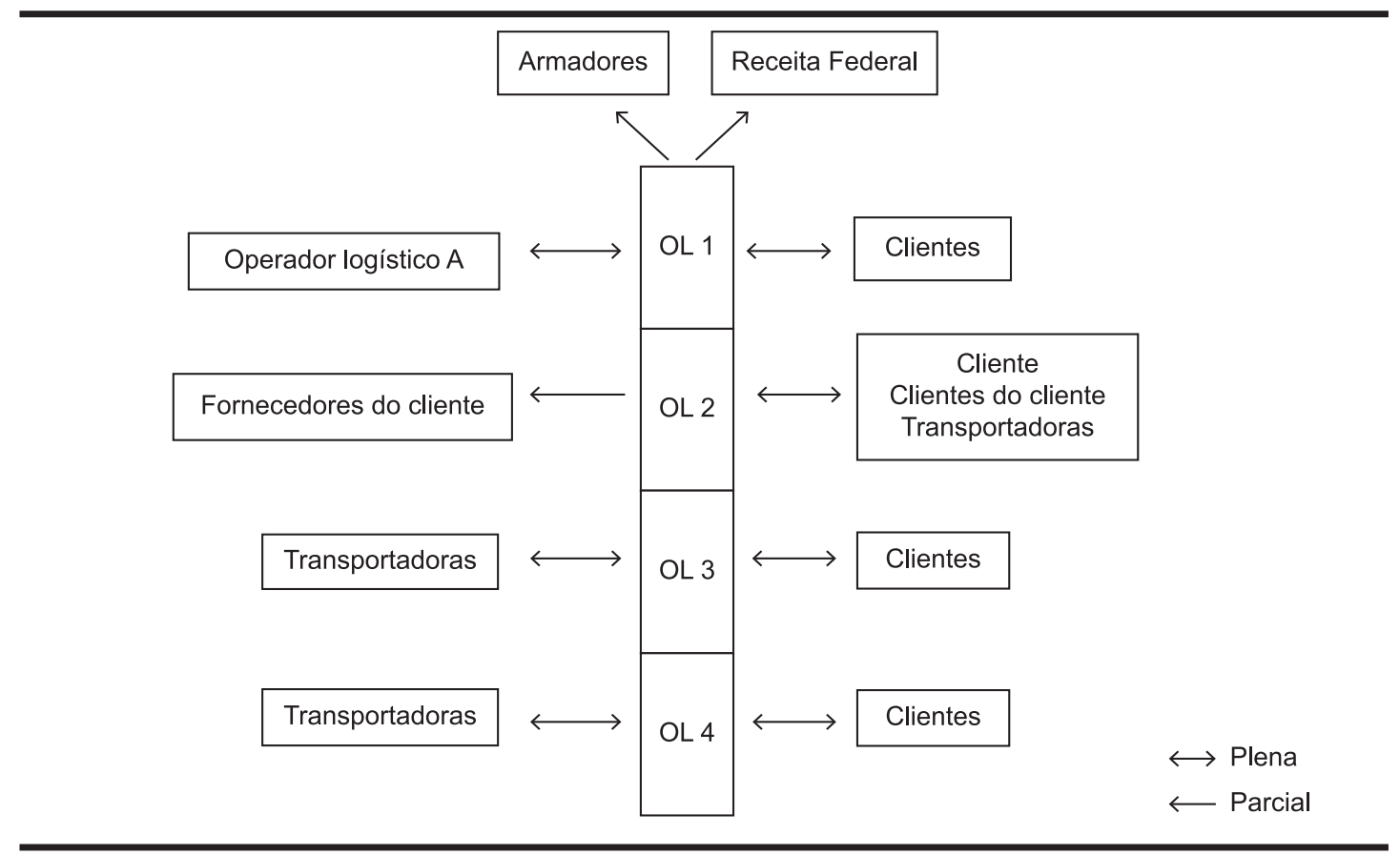

Figura 4. Integração entre operadores e outros agentes da rede. Fonte: Branski (2008). 


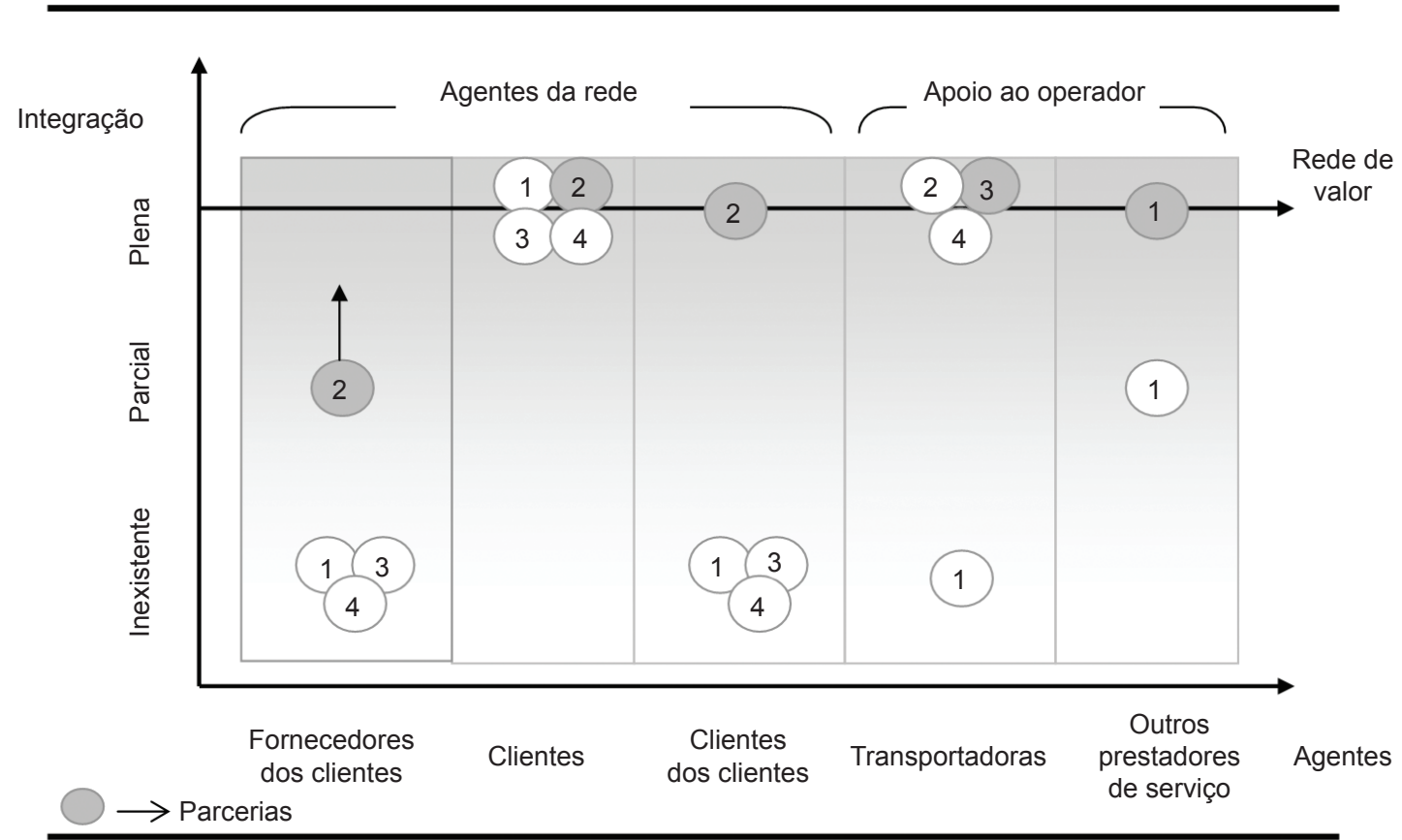

Figura 5. Modelo de integração externa dos operadores logísticos e outros agentes da rede. Fonte: Branski (2008).

estabelecidas com os agentes da rede constituem redes de valor.

Na Figura 5, é possível observar que OL 2 está plenamente integrado ao seu cliente, clientes do seu cliente e à transportadora, e, de forma parcial, aos seus fornecedores, além de identificar a existência de parcerias entre estes agentes. Nos demais operadores - OL 1, OL 3 e OL 4 -, ocorre integração plena com os clientes e transportadoras, mas, praticamente, inexiste integração com os demais agentes. Assim, por suas particularidades, a rede logística de OL 2 é a que mais se aproxima de uma rede de valor. Nos demais operadores, foram identificados segmentos de rede de valor, etapas em que os agentes operam de forma colaborativa e estão interligados digitalmente e que podem, futuramente, evoluir para uma rede plena.

\section{Considerações finais}

Para que os operadores possam aumentar sua competitividade, reduzindo seus custos e melhorando seus serviços, é essencial a integração, não só das diversas atividades logísticas (transporte, controle do estoque, gestão da distribuição etc.), como também nos seus processos com outros agentes da rede (fornecedores, clientes e seus clientes, transportadoras etc.). Integração, por sua vez, decorre da partilha de informação apoiada pelas tecnologias que colocam as bases para o estabelecimento de redes. Portanto, a TI é central para a promoção de colaboração entre empresas e para estimular a formação de redes.
Embora as tecnologias sejam necessárias para a melhoria, tanto dos processos internos dos operadores como também de suas cadeias de suprimentos, o investimento em TI, por si só, não garante um bom desempenho e, tampouco, a constituição de redes de valor. Os operadores precisam gerenciar de forma efetiva a informação, integrando as várias atividades logísticas para melhorar os fluxos de produtos físicos de seus clientes. Neste sentido, a partilha de informação é um elemento central, interligando as diferentes partes da sua rede logística e contribuindo para a colaboração entre os parceiros.

O trabalho apresentou um modelo, construído a partir dos elementos levantados em um estudo com quatro operadores logísticos, que facilita a identificação dos diversos agentes da rede logística, o estágio da integração externa verificado entre eles e os operadores logísticos, e as relações de parcerias estabelecidas. O modelo contribui, ainda, para o entendimento da partilha de informação entre os agentes, assim como para a análise e comparação da evolução de diferentes operadores em direção ao estabelecimento de redes de valor.

O modelo propõe uma classificação das fases de integração na rede baseada na partilha de informação entre os agentes, mas não analisa o tipo de informação partilhada, se transacional, operacional ou estratégica. Novos estudos que categorizassem o tipo de informação podem contribuir para melhor entendimento das relações entre as empresas e da dinâmica do negócio. 
Outros aspectos são importantes e podem ser aprofundados em novos estudos. Entre os quais:

- Funcionalidades das tecnologias de informação empregadas e das customizações realizadas pelos operadores. Estudos com este enfoque podem contribuir para melhor entendimento das necessidades tecnológicas dos operadores e para o desenvolvimento de aplicativos que atendam a elas;

- Análise dos desafios enfrentados pelos operadores para a integração das suas redes, formas de enfrentamento utilizadas, resultados obtidos e impactos sobre a sua competitividade; e

- Identificação e análise da contribuição dos operadores para a disseminação das tecnologias para outros agentes da rede. Este aspecto pôde ser observado na pesquisa - OL 2 introduziu novas soluções para seu cliente e fornecedores e OL 3, para as transportadoras - e merece ser melhor explorado.

Finalmente, cabe ressaltar que a pesquisa trabalhou com uma amostra reduzida e, por isso, as conclusões não podem ser generalizadas e se aplicam exclusivamente aos casos estudados (YIN, 2010). Apesar desta limitação, a compilação e análise dos resultados obtidos forneceu elementos para a elaboração de um modelo que deve, posteriormente, ser testado em novas pesquisas. Neste sentido, a inclusão de novos operadores e estudos voltados para o entendimento das redes em diferentes setores podem contribuir para verificar a validade e a aderência do modelo proposto, assim como ajudar na identificação de novos elementos que o tornem mais abrangente.

\section{Referências}

BAILEY, K.; FRANCIS, M. Managing information flows for improved value chain performance. International Journal of Production Economics, v. 111, p. 2-12, 2008. http://dx.doi.org/10.1016/j.ijpe.2006.11.017

BALLOU, R. H. The Evolution and Future of Logistics and Supply Chain Management. European Business Review, v. 19, n. 4, p. 332-348, 2007. http://dx.doi. org/10.1108/09555340710760152

BOURLAKIS, M.; BOURLAKIS, C. Integrating logistics and information technology strategies for sustainable competitive advantage. Journal of Enterprise Information Management, v. 19 n. 4, p. 389-402, 2006. http://dx.doi.org/10.1108/17410390610678313

BOVET, D.; MARTHA, J. Redes de valor. São Paulo: Negócio Editora, 2001.

BOWERSOX, D. J.; CLOSS, D. J.; STANK, T. P. 21st Century Logistics: making supply chain integration a reality. Oak Brooks: Council of Logistics Management, 1999.

BOWERSOX, J. D.; CLOSS, D. J. Logística Empresarial: o processo de integração da cadeia de suprimentos. São Paulo: Editora Atlas, 2001.
BRANSKI, R. M. O papel da Tecnologia de Informação no processo logístico: estudo de casos com operadores logísticos. 2008. 272 f. Tese (Doutorado)-Engenharia de Produção da Escola Politécnica, Universidade Estadual de São Paulo, 2008.

BRANSKI, R. M.; LAURINDO, F. J. B. Papel da tecnologia da informação na integração logística: estudo de caso com operador logístico. In: ENCONTRO NACIONAL DE ENGENHARIA DE PRODUÇÃO, 29., 2009, Salvador. Anais... Salvador, 2009.

BRANSKI, R. M.; AURELLANO, R. C. F.; LIMA JUNIOR, O. F. Metodologia de estudo de caso aplicada à logística. In: CONGRESSO DE PESQUISA E ENSINO EM TRANSPORTES (XXIII ANPET), 24., 2010, Salvador. Anais... Salvador, 2010.

BROWN, A. P. Qualitative method and compromise in applied social research. Qualitative Research, v. 10, n. 2, p. 229-248, 2010. http://dx.doi.org/10.1177/1468794109356743

CHANDRASHEKAR, A.; SCHARY, P. B.Toward the Virtual Supply Chain: the convergence of IT and organization. International Journal of Logistics Management, v. 10, n. 2, p. 27-39, 1999. http://dx.doi. org/10.1108/09574099910805978

CHENG, J. H. Inter-organizational relationships and information sharing in supply chains. International Journal of Information Management, v. 31, p. 374-384, 2011. http://dx.doi.org/10.1016/j. ijinfomgt.2010.09.004

CHOPRA, S.; MEINDL, P. Supply Chain Management: strategy, planning and operation. 4. ed. New Jersey: Prentice Hall, 2001.

CLOSS, D. J.; SAVITSKIE, K. International and External Logistics Information Techonology Integration. International Journal of Logistics Management, v. 14, n. 1, p. 63-76, 2003. http://dx.doi. org/10.1108/09574090310806549

FINK, L.; NEUMANN, S. Exploring the perceived business value of the flexibility enabled by information technology infrastructure. Information \& Management, v. 46, p. 90-99, 2009. http://dx.doi.org/10.1016/j. im.2008.11.007

GAO, L.; QI, E. Study on Cooperative Logistic Information System According to Supply Chain Management. Automation and Logistics. IEEE International Conference, p. 2576-2579, 2007. http://dx.doi. org/10.1109/ICAL.2007.4339014

GERRING, J.; McDERMOTT, R. An experimental template for case study research. American Journal of Political Scince, v. 51, n. 3, p. 688-701, 2010. http://dx.doi. org/10.1111/j.1540-5907.2007.00275.x

GRAWE, S. J. Logístics Innovation: a literature-based conceptual framework. The International Journal of Logistics Management, v. 20, n. 3, p. 360-377, 2009. http://dx.doi.org/10.1108/09574090911002823

GUNASEKARAN, A.; LAI, K.; CHENG, T. C. E. Responsive supply chain: a competitive strategy in a networked economy. Omega, v. 36, p. 549-564, 2008. http://dx.doi.org/10.1016/j.omega.2006.12.002

JHINGRAN, A. D.; MATTOS, N.; PIRAHESH, H. Information Integration: a research agenda. IBM 
Systems Journal, v. 41, n. 4, p. 555-562, Oct 2002. http://dx.doi.org/10.1147/sj.414.0555

KENGPOL, A.; TUOMINEM, M. A framework for group decision support systems: an application in the evaluation of information technology for logistics firms. International Journal of Production Economics, n. 101, p. 159-171, 2006. http://dx.doi.org/10.1016/j. ijpe.2005.05.013

KUPFER, D.; HASENCLEVER, L. Economia Industrial: fundamentos teóricos e práticas no Brasil. Rio de Janeiro: Editôra Elsevier, 2002.

LAUDON, K. C.; LAUDON, J. P. Management Information Systems: managing the digital firm. 8th ed. New Jersey: Prentice Hall, 2007.

LAURINDO, F. J. B. Tecnologia da informação - Planejamento e gestão de estratégias. São Paulo: Editora Atlas, 2008. 382 p.

LAURINDO, F. J. B.; MESQUITA, M. A. Material Requirements Planning: 25 anos de História - Uma Revisão do Passado e Prospecção do Futuro. Gestão \& Produção, v. 7, n. 3, dez. 2000. http://dx.doi.org/10.1590/ S0104-530X2000000300009

LIN, W. T. The business value of information technology as measured by technical efficiency: Evidence from country-level data. Decision Support Systems, v. 46, p. $865-874$, 2009. http://dx.doi.org/10.1016/j. dss.2008.11.017

NGAI, E. W. T.; LAI, K.; CHENG, T. C. E. Logistics information systems: The Hong Kong experience. International Journal of Production Economics, v. 113 , p. 223-234, 2008. http://dx.doi.org/10.1016/j. ijpe.2007.05.018

SCHOENHERR, T. Logistics and supply chain management application within a global context: an overview. Journal of Business Logistics, v. 30, n. 2, p. 1-25, 2009. http:// dx.doi.org/10.1002/j.2158-1592.2009.tb00109.x

SO, S.; SUN, H. Supplier integration strategy for lean manufacturing adoption in electronic-enabled supply chains.
Supply Chain Management, v. 15, p. 474-487, 2010. http://dx.doi.org/10.1108/13598541011080455

SWAFFORD, P. M.; GHOSH, S.; MURTHY, N. Achieving supply chain agility through IT integration and flexibility. International Journal of Production Economics, n. 116, p. 288-297, 2008. http://dx.doi.org/10.1016/j. ijpe.2008.09.002

TURBAN, E.; REINER, R. K.; POTTER, R. E. Administração de Tecnologia da Informação: teoria e prática. 4. ed. Rio de Janeiro: Elvesier, 2003.

VENKATRAMAN, N. IT-Enabled Business Transformation: from automation to business scope redefinition. Sloan Management Review, v. 35, n. 2, p.73-87, winter 1994.

VERDECHO, M. J. et al. The analytic network process for managing inter-enterprise collaboration: a case study in a collaborative enterprise network. Expert Systems with Applications, v. 39, p. 626-637, 2012. http://dx.doi. org/10.1016/j.eswa.2011.07.054

VIJAYASARATHY, L. R. An investigation of moderators of the link between technology use in the supply chain and supply chain performance. Information \& Management, v. 47, p. 364-371, 2010. http://dx.doi. org/10.1016/j.im.2010.08.004

WANGA, E. T. G. et al. Improving Enterprise Resource Planning (ERP) Fit to Organizational Process Through Knowledge Transfer. International Journal of Information Management, v. 27, n. 3, p. 200-212, 2007. http://dx.doi.org/10.1016/j.ijinfomgt.2007.02.002

XU, Q.; MA, Q. Determinants of ERP implementation knowledge transfer. Information \& Management, v. 45, p. 528-539, 2008. http://dx.doi.org/10.1016/j. im.2008.08.004

YIN, R. K. Estudo de caso: planejamento e métodos. 4. ed. São Paulo: Editora Bookman, 2010.

YUCESAN, E. The Impact of Information Technology on Supply Chain Management. Trends in Supply Chain Design and Management: Technologies and Methodologies, 2007. 